\title{
SOME EXPERIENCES IN EQUIPPING THE LABORATORY.
}

\author{
By W. E. Bowers. \\ Department of Science, Willmar (Minn.) High School.
}

While the more elaborate and expensive pieces of apparatus must always be made by skilled specialists, and supplied by the dealer in apparatus, wonders can be accomplished in the way of "home-made" apparatus by the enthusiastic teacher and the ingenious pupil. But these rude devices and fantastic make-shifts are fast giving way to apparatus that is substantial, durable and accurate, and that requires the application of skilled labor. It is the purpose of this paper to suggest a means of securing apparatus of this character at a comparatively small outlay, and to make a modest plea for the policy the writer has found thoroughly successful during the past three years.

While there is everywhere a gratifying tendency to add to the laboratory equipment, too many schools; especially small schools, spend their money for a few pieces of expensive factory-made apparatus, and then worry along with one micrometer and one vernier caliper, one balance, two pneumatic troughs, and three ring stands, in a laboratory where a dozen or half-dozen of each is necessary for convenient work; or they put the money into illustrative apparatus, and do without many things necessary for individual, especially quantitative work. It is, however, the conviction of the writer that, with the exception of chemicals (which may be bought through the drug store), rubber goods, glassware, and the elaborate pieces of apparatus, the laboratory may be well equipped, and very little money sent outside the city limits.

The objection may at once be raised that there is no one to do this kind of work; yet this objection usually soon disappears upon earnest and enterprising inquiry. Few towns large enough to have a high school, are without a gun shop, a bicycle shop, or a foundry, where some workman may be found who is able and willing to do all kinds of metal work, if the design is furnished by the teacher. Often this workman is a skilled machinist: occa- 
sionally he proves to be an immigrant from Europe, where he has had training in the very work required. Not infrequently he is a graduate of the local high school, or a college student, well versed in science, able not only to make, but also to design, apparatus, easy to interest in the work of the high school, and glad to be of service to the teacher and the school.

Such workmen can furnish, for practice in measurement, hardened steel rods, stamped and numbered, and turned so true that they will bear a micrometer test in any dimension, at. a few cents each. An oxyhydrogen blowpipe, made after the drawing given in most texts, will cost less than a dollar. If desirable, it may be made so as to be taken apart to show the construction. Bunsen burners can be had for about the same price, or even less; and five or six dollars will get a dozen ring stands, each with a 20 -inch rod and three or four welded rings, enameled throughout.

The best bargains and the best apparatus are in specific gravity balances. Only a faithful and a first-class workman can be trusted with the difficult task of making, adjusting and balancing so delicate a piece of apparatus. The writer has had three sets made at prices ranging from $\$ 8$ to $\$ \mathrm{I} 8$ for half dozen lots. Although the balances of the first lot were too small and too sensitive for the best results (easily sensitive to the graphite used in writing name and address), they were fairly satisfactory, and those of the last lot are highly so (experience has improved the design).

Each has a cast-iron base of neat design, and standard of small bicycle tubing (steel, 12 inches high), both enameled. The sliding telescope rod is of cold-drawn steel, the block for the bearings is sawed and drilled from steel bar and hardened; the Io-inch beam, knife-edges, pivot bearings, pointer, scale and beam arrester are likewise of hardened steel. These parts are well finished and have a polish equal to that of a good grade of shears. The pans are of spun brass, suspended on spring brass wire, of two heights, with hooks. They are bronzed and look fairly well; the appearance of the pans is the only particular in which they do not excel factory-made balances of medium quality.

These balances were made in the gun shop in this place and 
are strong, durable, sensitive to one centigram, and equal in utility to the factory-made balances listed at much higher prices. By actual test they compare without discredit, at least while new, with certain balances which were listed at $\$ 7, \$ 8$ and $\$ 16$ each.

The same workman could, if desired, make compasses, dividers, simple calipers, pendulums, models of pulleys, ring and ball apparatus, siren disc, and many other similar instruments, even a whirling table, screw press, hydraulic press, and model of steamengine-all at reasonable prices. Of course, this policy may be carried too far; most electrical apparatus, sets of metric weights, etc., are best purchased from a dealer.

Several arguments may be urged in favor of this policy. Strange as it may seem, quality of apparatus is an object but in few cases; economy of expenditure is the main thing to be gained. Then, too, an order of this kind is always a patronage of home industry, a reminder that the high school is not a dead weight on the community, and it always tends to attract the more cordial support of public-spirited citizens, as well as of the business men, workmen and school officers.

In a series of articles to follow, the writer will give working drawings and specifications for the construction of a number of pieces of apparatus that his experience has shown can be made sátisfactorily by any skilled mechanic.

\title{
WHAT CAN BE DONE WITH A SUNBEAM.
}

\author{
By A. E. Dolbear. \\ Professor of Physics, Tufts College.
}

Everybody knows of the magic lantern and its possibilities in a school-room, but many do not know what can be done with a sunbeam and a few dollars' worth of proper fixtures in the same place. Let me indicate briefly how little is really needed in order to obtain pictures which rival those from a costly lantern and an electric arc light.

I will assume a school-room into which the sun will shine 